\title{
Sea level in the late Quaternary: patterns of variation and implications
}

\author{
W. H. Berger
}

Received: 23 February 2007/Accepted: 23 November 2007/Published online: 17 July 2008

(C) The Author(s) 2008

\begin{abstract}
Studies of oxygen isotopes in foraminifers from deepsea sediments yield information about rates of change of sea level, for hundreds of thousands of years with a resolution of roughly 1,000 years. The statistics regarding fluctuations for the late Quaternary (the last 900,000 years) suggest that a rise of $10 \mathrm{~m}$ per 1,000 years $(1 \mathrm{~m}$ per century) is not unusual, even when the system resides within a warm stage, as now. Values near $2 \mathrm{~m}$ per century, while rare, are well within the range of a warm system, beyond the 5-percentile of the overall range. Once sea level is near $+10 \mathrm{~m}$, further rise becomes highly unlikely within the conditions of the late Quaternary, suggesting the presence of some kind of natural barrier; that is, lack of vulnerable ice. The present volume of ice generally considered vulnerable (Greenland and West-Antarctic ice sheet) adds up (roughly) to the observed limit.
\end{abstract}

Keywords Sea level - Deep sea sediments .

West Antarctic ice sheet

\section{Introduction}

In the third assessment of the ICPP (Houghton et al. 2001), on the 1,000-year scale, substantial melting of Greenland's ice sheet is anticipated (contributing ca. $6 \mathrm{~m}$ of sealevel rise), while stability of the West-Antarctic ice sheet is thought to restrict a 1,000-year rise from this source to $3 \mathrm{~m}$

\section{W. H. Berger $(\bowtie)$}

Scripps Institution of Oceanography,

University of California,

San Diego, CA 92093-0244, USA

e-mail: wberger@ucsd.edu or less (Church et al. 2001). Thus, on this time scale, the projection of the average rise per century in the future lies between 0.6 and less than $1 \mathrm{~m} /$ century. The authors point out that ice dynamics are as yet "inadequately understood" for the purpose of making "firm projections, especially on the longer time scales" (p. 642). The statement implies that a better understanding of ice dynamics will greatly improve projections in the future, especially on longer time scales. This may be so; however, what matters is not only the gradual rise from water expansion and meltwater from mountain glaciers but also the risk from collapse of large ice sheets, as seen in rapid deglaciation (Denton and Hughes 1981; Seidov et al. 2001). The most vulnerable ice to provide for such collapse would seem to be the Greenland ice sheet, for a potential sealevel rise of about $7 \mathrm{~m}$ (Church and Gregory 2001). Another possible source of sealevel rise, slightly less massive, is the West-Antarctic ice sheet.

It seems likely that the timing of ice sheet collapse will not yield to deterministic calculations emphasizing gradual change. In fact, in a recent paper assessing the impact of model physics on estimating the surface mass balance of the Greenland ice sheet (Bougamont et al. 2007), the authors imply that without the inclusion of ice dynamics there can be no attempt to predict the future behavior of the ice sheet (ibid., p. 2 of 5), which entails severe limits on the efficacy of physical models. Presumably, we are dealing with gravitationally unstable systems with complex internal nonlinear feedbacks. We would expect unpredictable response to steady forcing (warming), informed by stochastic stimulation (e.g., earthquakes). Within such a conceptual framework, quasi-deterministic computations become more or less irrelevant to the problem of accelerated sealevel rise, while past behavior gains in importance. Quite generally, the importance of abrupt change, as seen 
in the geologic record, may have been underestimated in assessing the risks associated with global warming (Alley et al. 2005).

In what follows, I present statistics on the rates of sealevel change within the past 900,000 years, based on published oxygen isotope data (Zachos et al. 2001). Many similar data sets are available for analysis; this one seemed to be the most comprehensive. Such series provide a sense of behavior of sea level on the 1,000-year scale, within the currently reigning geologic framework of climate conditions. When transferred to the century scale, results may be considered conservative relative to risk analysis, since they reflect the mean behavior over many centuries, smoothing away any unusual excursions; that is, events that carry risk. The patterns observed show a familiar asymmetry; the rates for rises in sea level are generally larger than those for falls, reflecting the fact that building ice takes longer than melting it. A number of possible causes for this observation have been put forward, some involving changes in ocean currents and heat transport and other feedbacks (see review by Alley and Clark 1999, and articles in Seidov et al. 2001). The simplest explanation is that the buildup of ice is accompanied by buildup of instability (Berger 1999).

If instability increases with time, as suggested by the more or less regular spacing of major deglaciation events ("terminations," Broecker and van Donk 1970) ice dynamics must depend to some degree on the age of the ice caps to be melted, and not just on the warmth of summers. We have, within the ice-age cycles, an increase in the "vulnerability" of ice; that is, its readiness to respond to warming. This notion of the importance of age of ice mass can help explain the "Stage 11 Problem" identified by Imbrie and Imbrie (1980). In fact, in the explanation proposed (Berger 1997, 1999; Paul and Berger 1999) it is not the age of existing ice that matters, but the mass of the average ice of the previous 50,000-60,000 years. Put differently, it is the growing vulnerability of ice through tens of thousands of years, as its growth and presence modifies the boundary conditions that govern stability.

The hypothesis underlying the present essay is that the vulnerability of all of the ice that participates in the ice-age fluctuations is set by the immediate geologic past (tens of thousands of years), independently of the existing ice mass, and that there is a large amount of ice not subject to the vulnerability cycles. This, it is here proposed, is the reason why the potential for rates of sealevel rise exceeding $1 \mathrm{~m} /$ century is undiminished during periods of high stand (as at present), and why the maximum high stand reached in the last 900,000 years is near $+10 \mathrm{~m}$. Presumably, it is the East Antarctic ice sheet that is the mass not participating in the vulnerability cycles, in agreement with the assessment that it is the most stable part of the changing system (Church et al. 2001).

\section{Data sets and methods}

The typical distance between individual data points in the 900-year data set used (from a compilation of Zachos et al. 2001 ) is $1.05 \pm 0.3 \mathrm{kyr}$. After applying a 111 boxcar smoothing, this set was converted to a spacing of $1 \mathrm{kyr}$ by interpolation within a gliding window of four points, along a fit defined by the four points (the differences to straight interpolation between pairs of data points are small). The resulting curve (Fig. 1) is familiar from many "stacks" of isotopic stratigraphies, including the "SPECMAP" stack published by Imbrie et al. (1984), which is valid for the Milankovitch chron (that is, the last third of the Quaternary, the period discussed by Milankovitch 1930). The series agrees well with other similar sequences (Bassinot et al. 1994; Mix et al. 1995; Waelbroeck et al. 2002; Berger 2003), down to fine detail. It reflects, in essence, the growth and decay of ice (three-fourths of the signal) as well as temperature and salinity changes in the deep-sea (approximately one-fourth of the signal seen). The periodicities observed suggest an oscillation of the earth's climate system centered near $100 \mathrm{kyr}$, and in resonance with periodic forcing based on orbitally controlled summer insolation in high latitudes, a forcing first proposed by Milankovitch (1930). An artificial series fitting the observed one is readily generated when assuming that high-summer insolation at high latitudes (as in Berger and Loutre 1991) is the driving variable, and that the response of the climate machine is predicated upon "listening" to extremes in the forcing during privileged periods of instability, but not listening very much during other times (Berger et al. 1996).

Geologically speaking, the "present" is comprised by the last 900,000 years; that is, the period with long-term climate fluctuations based on long-term oscillations (it is the internal oscillations that change at the mid-Pleistocene climate shift, not the external astronomical forcing). Warm extremes such as the Holocene (note 5\% line) are restricted to the Milankovitch chron (last 650,000 years), which is initiated by the largest glaciation ever (MIS 16). It is readily seen that this period is characterized by an expansion of the range of fluctuations in both directions, up and down. Because of this expansion, the analysis of patterns within warm extremes is de facto restricted to the Milankovitch chron. More precisely, it is restricted largely to the last two-thirds of that period, following the MIS-12 climate shift. It is after this shift that warm extremes occur with regularity. One of these extremes is our own Holocene (MIS 1).

The record of oxygen isotopes (Fig. 1) is that of shells of benthic foraminifers on the deep-sea floor, from various parts of the ocean, and measured by various laboratories. No effort was made here to treat the uncertainties arising from pooling the data. The signal is largely informed by ice 
Fig. 1 Oxygen isotope record of the late Quaternary (last 900,000 years). Brunhes chron: last magnetic period, started 790,000 b.p.; Milankovitch chron: time from Stage 16 (largest glaciation of the Quaternary); Mid-Pleistocene climate shift: system moves into long-term ice-age cycles; Numbers: stage labels (MIS, marine isotope stage)

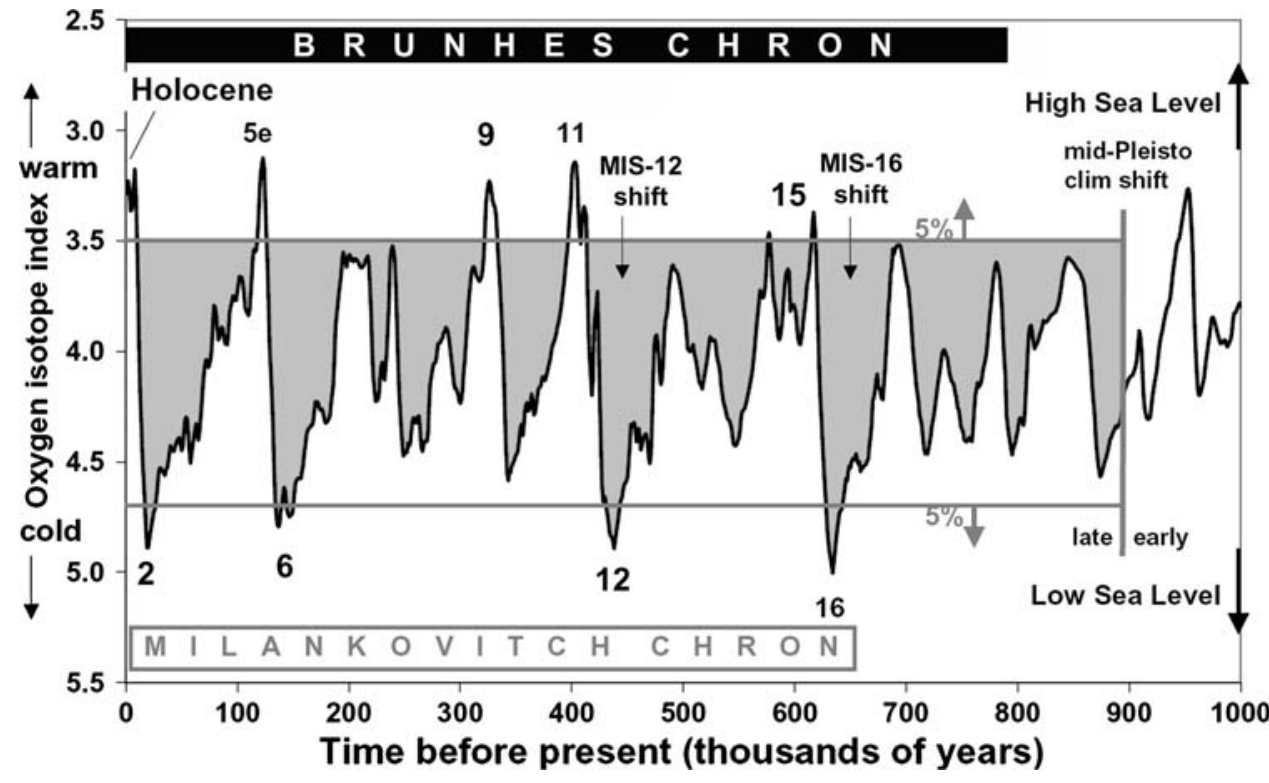

mass and associated sealevel change, but also reports on other parameters such as temperature and salinity. These complications are not considered here in converting the isotopic signal to sealevel variation. Instead, I use the conventional estimate of $120 \mathrm{~m}$ of change from the last glacial maximum to the present (Mix and Ruddiman 1984; Chappell and Shackleton 1986; Fairbanks 1989, and earlier work cited in Shepard 1963, and in Matthews 1990). For a $\delta^{18} \mathrm{O}$ range of 1.6 permil between the last glacial and the Holocene (Fig. 1), this assumption provides a calibration of a difference in sea level of $7.5 \mathrm{~m}$ for a difference of isotopes of 0.1 permil in the data set at hand. Assuming that the other factors influencing isotope values (temperature, salinity) have variations that preserve aspect ratios with oxygen isotopes throughout their range and stay in phase for all of the late Pleistocene, this calibration can be used for the entire period. The assumption of linearity has been tested by modeling (Sima et al. 2006); the error arising from changes in the isotopic composition of the varying ice mass seems to be modest $(<10 \%)$. Any lag between icemass variation and oxygen isotopes does not affect the arguments here presented.

\section{Statistical patterns and implications}

The major part of the range of variation appears quite well defined, especially for the Milankovitch chron (Fig. 1). This suggests the operation of negative feedback at the edges of that range (boundary for gray field). In addition, trends of ice buildup (drops in sea level) persist for tens of thousands of years, indicating self-stabilization of trends, as a result of positive feedback. The iconic example for the dominance of internal dynamics in shaping the cycles is Stage 11, for which outside forcing is at a minimum because of low eccentricity of Earth's orbit (Berger and Wefer 2003). The undiminished range seen in the transition from Stage 12 to 11 is remarkable. It highlights a major argument of this essay; ice melts readily when conditions are right, even with modest outside forcing.

Stage 11, given its orbital configurations, has great similarity to Stage 1 (Berger and Loutre 2003). However, the Stage 11 sealevel highstand has not been reached in the Holocene. The anthropogenic forcing (excess greenhouse effect) presumably favors moving in that direction, with a target of $+7 \mathrm{~m}$ relative to late Holocene sea level. This corresponds roughly to the ice mass of Greenland. The rate of rise, in approaching the peak of Stage 11, was near $1 \mathrm{~m} /$ century, for at least a 1,000 years. External forcing was minimal. For comparison with the addition of external forcing (Stage 5e) the target is $+10 \mathrm{~m}$, and the rate of rise is the same, but for longer. In summary, the record suggests that our own situation is one with a target of about +10 , and a rate of rise of $1 \mathrm{~m} /$ century. The suggestion is that this target needs to be considered in terms of risk that adds to the projections generated by assessments based on seawater expansion from warming and on melting mountain glaciers. Exactly when the present sealevel rise will accelerate to the deglaciation mode is not known, and is presumably unpredictable on the time scales of interest (a century or less). All we know is that the risk can be roughly defined from history and that it rises with warming and with length of time.

A more detailed look at the patterns of the isotope record strengthens the suggestion that a rise of $1 \mathrm{~m} /$ century or more is well within the range of possibilities, as elaborated in what follows. 
The long-term persistence of trends within the common range of variation suggests the operation of positive feedback stabilizing the trends. If this is so, we should expect a distribution of sealevel positions that avoids intermediates. Also, if there is a zone where positive feedback changes to negative, close to the edges of the main range of variation, we should see a pile-up of abundances of sealevel positions in that zone. The patterns observed support the concept of a large range dominated by positive feedback and limited by zones where negative feedback rules (Fig. 2). Avoidance of intermediate conditions is indicated by the lack of a bulge in the central portion of the range. Instead, the distribution of positions within the major range is trapezoid to rectangular to a first approximation, with some indication of pileup near the boundaries, especially at the lower end of the common range.

The nature of limitations at the boundaries of the common range is of interest, especially at the upper end, near $-20 \mathrm{~m}$. Negative feedback seems indicated, or else there is a shortage of unstable ice beyond that level. There are not enough cases in this regime $(n=50)$ to distinguish these two collaborating factors. The pattern suggests that once a threshold is crossed, positive feedback is no longer dominant, but within the new regime there is no strong preference for any one position, between roughly $-10 \mathrm{~m}$ and $+5 \mathrm{~m}$. In other words, the negative feedback is weak in this band. But it sets in very strongly at $+10 \mathrm{~m}$.

The simplest description of the pattern is that, at the present position of sea level, the system is indifferent to modest change, where "modest change" comprises a few meters of sealevel change, capped with a sharp upper limit near $+10 \mathrm{~m}$; that is, roughly the combined mass of ice in Greenland and in the West Antarctic.
With respect to the anticipated effects for global warming, this would mean that under present conditions the melting of an ice mass equivalent to that of Greenland is not opposed by strong negative feedback, but the melting of a mass exceeding the combined masses of Greenland and the West Antarctic ice sheet is so opposed.

We next take a closer look at the distribution of rates of change within the warm five percentile of the data set, beyond the feedback transition zone. The question is, are these rates lower or higher, on the whole, than is typical for the entire range. The answer is that they are roughly the same, but with some indication for larger variability (Fig. 3).

The pattern for all points $(n=900)$ shows that a slow fall of sea level $(-0.1 \mathrm{~m} /$ century $)$ is the most common situation for the late Quaternary, and the pattern for the warm side $(n=50)$ shows that this includes warm periods, as well. The distribution of rates of change supports the notion that ice tends to build all the time, unless prevented by special circumstances; that is, conditions involving summer melting combined with ice instability (Berger 1999; Paul and Berger 1999). Because ice instability represents lagged negative feedback, the system oscillates, and it does so asymmetrically. Because the melting is tied to warm summer conditions in high northern latitudes, instability becomes effective only during certain configurations of the planet's orbit and axis of rotation. Thus, the oscillation resonates with Milankovitch forcing.

Melting (i.e., sealevel rise) has larger extremes than buildup ( $2 \mathrm{~m} /$ century vs. $1.2 \mathrm{~m} /$ century; Fig. 3$)$, confirming the familiar asymmetry between the buildup and collapse of ice that was first emphasized by Broecker and van Donk (1970), on the basis of the oxygen isotope data
Fig. 2 Abundance distribution of sealevel positions. Positive and negative feedback regimes are separated by abrupt change in abundance of positions. Note that the position of present sea level is well outside the common range. Also, note the absence of a central bulge

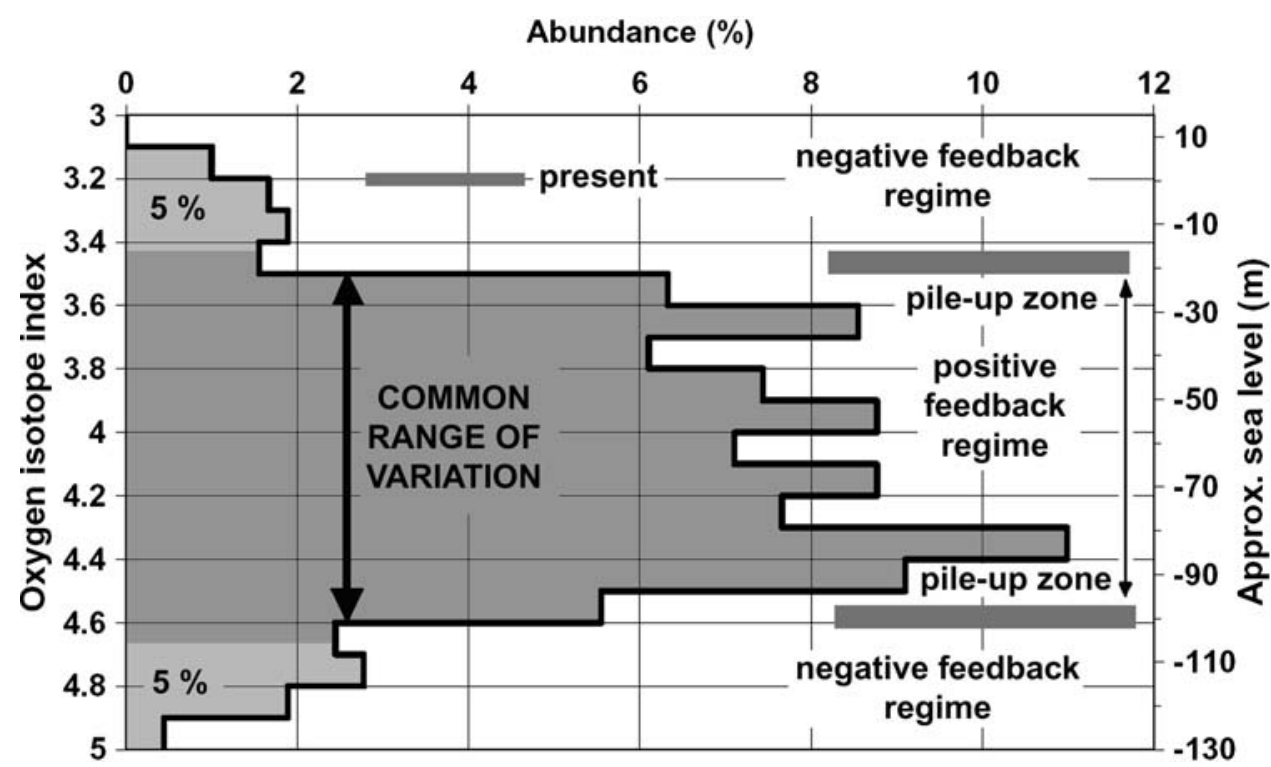


Fig. 3 Abundance distribution of rates of change for all points $(n=900)$ and for the warm side $(n=50)$. Note the rough congruency, but with a greater spread in the smaller set

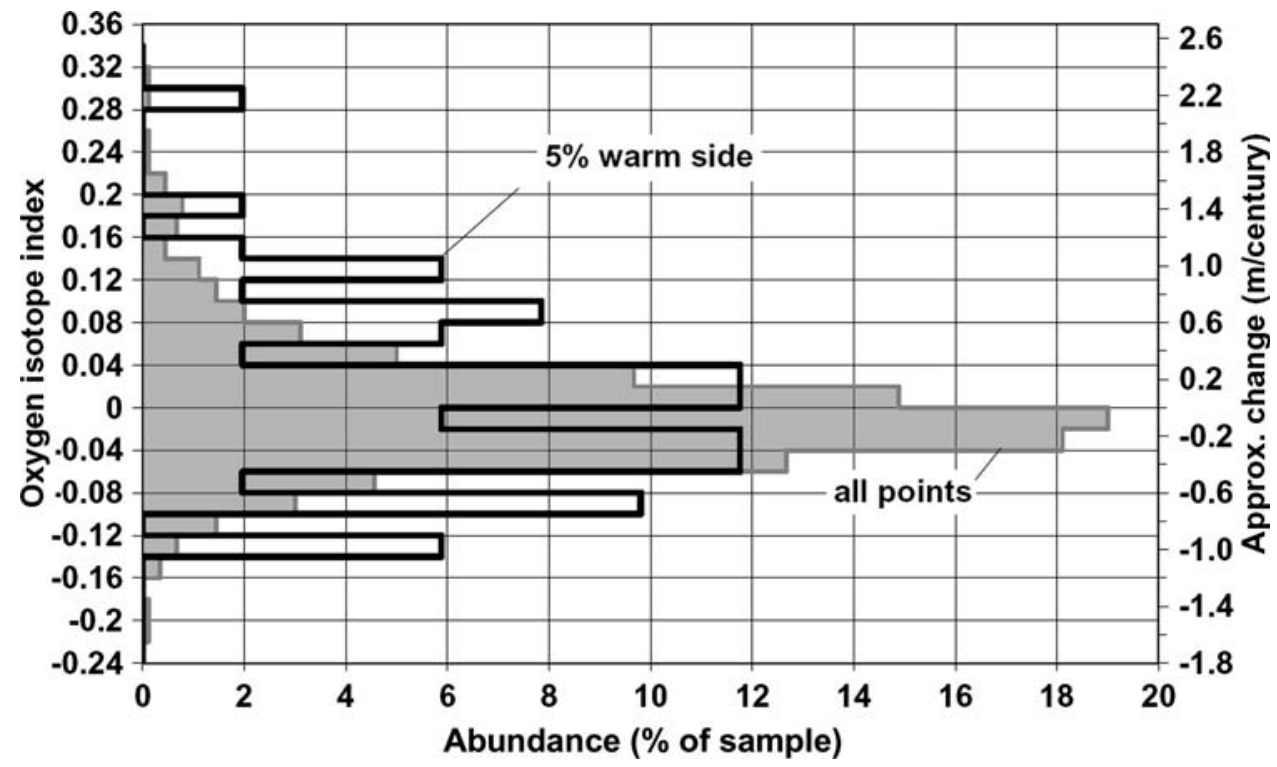

several principles readily emerge: (1) ice masses contain gravitational energy, which turns into heat when ice flows downhill, facilitating flow, (2) the downward transfer of summer melt, from the surface of an ice sheet into cracks where it can refreeze, represents a one-way heat pump, (3) meltwater can soften the ground below the ice or form puddles and lakes, which will decrease friction at the base and favor downhill gliding, and (4) saturating a glacier with meltwater facilitates gliding by the familiar pressure lift principle underlying large-scale landslides (Hubbert and Rubey 1959). The point is, like other solids moving downhill, glaciers are subject to the rules of mass wasting in the presence of fluid water. Together with isostatic sinking under the ice load (which brings the base of ice sheets at the margin into vulnerable positions below sea level), there are several mechanisms available to accumulate instability through time, until a threshold is reached for collapse.

The Heinrich Events show that large-scale collapse is part of the "normal" behavior on the time scale of ice-age cycles; the terminations show that collapse can occasionally comprise ice sheets of continental dimensions. Could the onset of such periods of ice collapse have been predicted a 100 years before they occurred? Answers to this question must be sought in analogy to landslide- and earthquake predictions, that is, in the statistics of stochastic events. Geologically speaking, the terminations arrived on time, stimulated by outside forcing. But the question of timing of the Heinrich Events is unresolved. In any case, the time scale of a century or less is not accessible in the type of data here analyzed.

How persistent are periods of rapid sealevel rise? Does the rate of rise in one millennium have information about the rate of rise in the millennium that follows? Plotting the Alley et al. 2005). The question is by no means settled, but 
change for 1 millennium against that of the following one allows us to find the patterns relevant to these questions (Fig. 4).

The distributions for all available pairs (Fig. 4a) shows that at any one time, the governing rate of change is likely to be the same as that in the previous millennium. It is as though the climate trend at any one time has inertia. This is not surprising, since the overall cycles have a length of between 20,000 and 100,000 years. In such long cycles, any millennium is bound to be much like the previous one, whether changes are small (plotting near the zero lines in Fig. 4a) or large (plotting near the extremes, but still close to the line labeled "no change").

The situation within the warm-end five percentile (Fig. 4b) is not at all congruent to that for the entire sampling space. In this case, as expected, there is a tendency for the second millennium in each pair to show a lesser rate of rise or a greater rate of fall than the previous millennium (by about $0.2 \mathrm{~m} /$ century). This is necessary if sea level is to turn around, near the upper bound of its
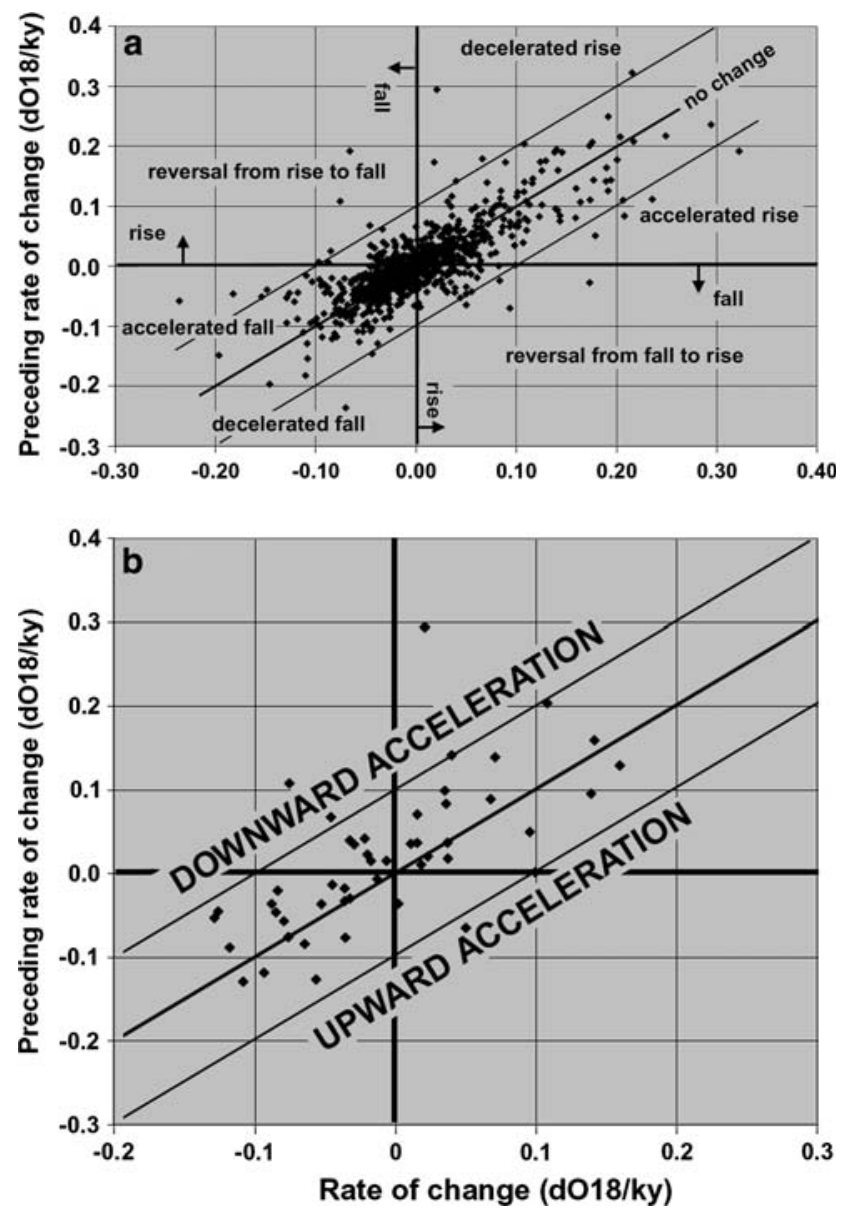

Fig. 4 Pattern of acceleration of rates in all available pairs (upper graph; $n=900$ ) and in the pairs within the warm zone (5 percentile; lower graph; $n=50$ ). Note persistence in (a), with points close to "no change" line, and offset in (b) range of positions. Interestingly, the pattern holds for the entire range of rates observed within the warm side set ( $n=50$ ); that is, the offset for the second member of each pair has roughly the same distribution over the range (Fig. 4b). As far as the sparse sampling allows this type of inference, it means that the background fall of sea level is steady over the range.

Within the set of points in the warm-end of distributions (Fig. 4b), the Holocene points are not obviously different from the rest (not shown), but the scatter and scarcity of points prevents confident assessment. Thus, there is no clear evidence from the present analysis for special conditions during the last several thousand years, along the lines proposed by Ruddiman (2005). He suggests that human impacts on the carbon cycle have kept the climate from substantial cooling (along with a fall in sea level), in the late Holocene. To decide this question, one would have to compare model output, proven to accurately represent climate fluctuations in the last 450,000 years on a millennial time scale, with evolution of climate in the Holocene. Until this is done, this very interesting question remains unresolved.

\section{Conclusions and relevance}

The main conclusions based on the descriptive statistics of the oxygen isotope record of the late Quaternary here offered and interpreted are as follows: (1) the particular quasi-rectangular (non-Gaussian) distribution of conditions within the late Quaternary suggests dominance of positive feedback within the main range of variation, and of negative feedback near the edges. Also, there is a strong indication of material limitation: a shortage of vulnerable ice beyond a sea level of $+10 \mathrm{~m}$, and a shortage of suitable space to grow additional ice beyond a sea level of $-130 \mathrm{~m}$, (2) the distribution of rates of sealevel change suggests an ever-present tendency to build ice, unless conditions are unfavorable, and shows an asymmetry confirming the concept that buildup is slower than decay of ice. The extremes of rates for collapse are near $2 \mathrm{~m} /$ century, on the millennial time scale, (3) the distribution of changes in rates show persistence from 1 millennium to the next, but also indicate that within the warm zone of ice-age conditions ( 5 percentile) there is a tendency to slow the rise and accelerate the fall of sea level, as expected. The typical difference from one millennium to the next, within this zone, corresponds to $-0.2 \mathrm{~m} /$ century; that is, twice the overall tendency for ice buildup.

In the context of discussions about the present and future behavior of sea level, it is of interest that patterns of change within the warm end (5 percentile) are not fundamentally different from patterns over the entire range (Fig. 3), 
except for greater scatter. This means that below a level of $+10 \mathrm{~m}$ (taking the present as zero) the opportunity for fast rise (1-2 m/century) persists. Fast rise of sea level is presumably tied to ice collapse, as this is certainly true for deglaciation, and probably also for Heinrich Events. The obvious candidates for such collapse are the Greenland ice sheet and the West Antarctic ice sheet. These ice masses are vulnerable owing to a combination of causes including groundings below sea level, potential access for seawater, low elevation, and temperature of the ice.

From the various discussions of possible causes of deglaciation and Heinrich Events, it appears that the collapse of ice masses is more closely related to the physics of mass wasting than to the physics of regular glacier flow. If so, this introduces a large element of uncertainty into the projections of sealevel rise for the future. Estimates of contributions to sealevel rise from changes in polar ice masses are routinely based on observing current behavior of ice sheets (Warrick et al. 1990; Houghton et al. 2001). This is somewhat analogous to employing the rate of soil creep in landslide-prone regions as an indication of slope stabilities in the area. While soil creep is not without interest, it is obviously not a fail-safe guide to slope stability. History and knowledge about internal structure is the better guide. Unfortunately, mass wasting events are difficult to predict. We know that they are favored by heavy rains (that is, by the addition of water to unstably positioned layered solids) and by earthquakes (that is, stochastic disturbance).

Open Access This article is distributed under the terms of the Creative Commons Attribution Noncommercial License which permits any noncommercial use, distribution, and reproduction in any medium, provided the original author(s) and source are credited.

\section{References}

Alley RB, Clark PU (1999) The deglaciation of the northern hemisphere: a global perspective. Annu Rev Earth Planet Sci 27:149-182

Alley RB, Clark PU, Huybrechts P, Joughin I (2005) Ice-sheet and sea-level changes. Science 310:456-460

Bassinot FC, Labeyrie LD, Vincent E, Quidelleur X, Shackleton NJ, Lancelot Y (1994) The astronomical theory of climate and the age of the Brunhes-Matuyama magnetic reversal. Earth Planet Sci Lett 126:91-108

Berger WH (1997) Experimenting with ice-age cycles in a spreadsheet. J Geosci Educ 45:428-439

Berger WH (1999) The 100-kyr ice-age cycle: internal oscillation or inclinational forcing? Int J Earth Sci 88:305-316

Berger WH (2003) Climate future in a warming world: lessons from the ice ages. In: Wernli RL Kennel CF (conveners), Celebrating the Past ... Teaming Toward the Future, Oceans 2003, CD ROM Proceedings. Holland Enterprises, Escondido, pp 404-408

Berger WH, Jansen E (1995) Younger Dryas episode: ice collapse and super-fjord heat pump. In: Troelstra SR, van Hinte JE, Ganssen GM (eds) The younger Dryas. North-Holland, Amsterdam, pp 61-105
Berger A, Loutre MF (1991) Insolation values for the climate of the last 10 million years. Quaternary Sci Rev 10:297-317

Berger A, Loutre MF (2003) Climate 400,000 years ago, a key to the future? In: Droxler AW, Poore RZ, Burckle LH (eds) Earth's climate and orbital eccentricity. American Geophysical Union, Washington DC, pp 17-26

Berger WH, Wefer G (2003) On the dynamics of the ice ages: stage11 Paradox, Mid-Brunhes Climate Shift, and 100-ky cycle. In: Droxler AW, Poore RZ, Burckle LH (eds) Earth's climate and orbital eccentricity: the marine isotope stage 11 question. Am Geophys (Union Geophys Monogr) 137:41-59

Berger WH, Bickert T, Yasuda MK, Wefer G (1996) Reconstruction of atmospheric $\mathrm{CO}_{2}$ from the deep-sea record of Ontong Java Plateau: the Milankovitch chron. Geol Rundschau 85:466-495

Bond GC, Lotti R (1995) Iceberg discharges into the North Atlantic on millennial time scales during the last glaciation. Science 267:1005-1010

Bond G, Heinrich H, Huon S, Broecker WS, Labeyrie L, Andrews J, McManus J, Clasen S, Tedesco K, Jantschik R, Simet C (1992) Evidence for massive discharges of icebergs into the glacial Northern Atlantic. Nature 360:245-249

Bougamont M, Bamber JL, Ridley JK, Gladstone RM, Greuell W, Hanna E, Payne AJ, Rutt I (2007) Impact of model physics on estimating the surface mass balance of the Greenland ice sheet. Geophys Res Lett 34(L17501):1-5

Broecker WS, van Donk J (1970) Insolation changes, ice volumes, and the $\mathrm{O}^{18}$ record in deep-sea cores. Review Geophys Space Phys 8:169-198

Chappell J, Shackleton NJ (1986) Oxygen isotopes and sea level. Nature 324:137-140

Church JA, Gregory JM (2001) Sea level change. In: Steele JH, Thorpe SA, Turekian KK (eds) Encyclopedia of ocean sciences, vol 6. Academic Press, San Diego, pp 2599-2604

Church JA, Gregory JM, Huybrechts P, Kuhn M, Lambeck K, Nhuan MT, Qin D, Woodsworth PL et al (2001) Changes in sea level. In: Houghton JT et al (eds) Climate Change 2001: the scientific basis. Contribution of Working Group I to the Third Assessment Report of the Intergovernmental Panel on Climate Change. Cambridge University Press, Cambridge, pp 639-693

Denton GH, Hughes TJ (eds) (1981) The Last Great Ice Sheets. Wiley, New York, p 48 (Maps)

Emiliani C (1955) Pleistocene Temperatures. J Geol 63:538-578

Emiliani C (1966) Paleotemperature analysis of Caribbean cores P6304-8 and P6304-9 and a generalized temperature curve for the past 425,000 years. J Geology 74(2):109-126

Emiliani C, Geiss J (1959) On glaciations and their causes. Geol Rundsch 46(2):576-601

Fairbanks RG (1989) A 17, 000 year glacio-eustatic sea level record: Influence of glacial melting rates on the Younger Dryas event and deep-ocean circulation. Paleoceanography 342:637-642

Heinrich H (1988) Origin and consequences of cyclic ice rafting in the Northeast Atlantic Ocean during the past 130, 000 years. Quaternary Res 29:143-152

Houghton JT et al (eds) (2001) Climate Change 2001: the scientific basis. Contribution of Working Group I to the Third Assessment Report of the Intergovernmental Panel on Climate Change. Cambridge University Press, Cambridge, $881 \mathrm{p}$

Hubbert MK, Rubey WW (1959) Role of fluid pressure in mechanics of overthrust faulting. Bull Geol Soc Am 70:115-166

Imbrie J, Imbrie JZ (1980) Modeling the climatic response to orbital variations. Science 207:943-953

Imbrie J, Hays JD, Martinson DG, McIntyre A, Mix AC, Morley JJ, Pisias NG, Prell WL, Shackleton NJ (1984) The orbital theory of Pleistocene climate: support from a revised chronology of the marine $\delta^{18} \mathrm{O}$ record. In: Berger AL, Imbrie J, Hays J, Kukla G, 
Saltzman B (eds) Milankovitch and cimate, vol 1. Reidel, Hingham, pp 269-305

MacAyeal DR (1993) Binge/purge oscillations of the Laurentide Ice Sheet as a cause of the North Atlantic's Heinrich Events. Paleoceanography 8(6):775-784

Matthews RK (1990) Quaternary sea-level change. In: Revelle RR (ed) Sea-Level Change. National Academy Press, Washington. DC, pp 88-103

Milankovitch M (1930) Mathematische Klimalehre und astronomische Theorie der Klimaschwankungen. Handbuch der Klimatologie, Bd 1, Teil A. Bornträger, Berlin, p 176

Mix AC, Ruddiman WF (1984) Oxygen-isotope analyses and Pleistocene ice volumes. Quaternary Res 21:1-20

Mix AC, Pisias NG, Rugh W, Wilson J, Morey A, Hagelberg TK (1995) Benthic foraminifer stable isotope record from Site 849 (0-5 Ma): local and global climate changes. In: Pisias NG, Mayer LA, Janecek TR, Palmer-Julson A, van Andel TH (eds) Proc. ODP, Scientific Results, 138. College Station, TX, Ocean Drilling Program, pp 371-412

Oerlemans J, van der Veen CJ (1984) Ice Sheets and Climate. Reidel, Dordrecht, p 217

Paul A, Berger WH (1999) Climate cycles and climate transitions as a response to astronomical and $\mathrm{CO} 2$ forcings. In: Harff J, Lemke W, Stattegger K (eds) Computerized modeling of sedimentary systems. Springer, Berlin, pp 223-245

Ruddiman WF (2005) Plows, plagues and petroleum. How humans took control of climate. Princeton University Press, Princeton and Oxford, p 202
Ruddiman WF, Molfino B, Esmay A, Pokras E (1980) Evidence bearing on the mechanism of rapid deglaciation. Clim Change 3:65-87

Seidov D, Haupt BJ, Maslin M (2001) The oceans and rapid climate change-past, present and future. Geophys Monogr 126:1-293

Shepard FP (1963) Submarine Geology. Harper and Row, New York, p 557

Sima A, Paul A, Schulz M, Oerlemans J (2006) Modeling the oxygenisotopic composition of the North American ice sheet and its effect on the isotopic composition of the ocean during the last glacial cycle. Geophys Res Lett 33, LI5706. doi: 10.1029/ 2006GL026923

Van der Veen CJ (ed) (1999) Fundamentals of glacier dynamics. Balkema, Rotterdam, p 462

Waelbroeck C, Labeyrie L, Michel E, Duplessy JC, McManus JF, Lambeck K, Balbon E, Labracherie M (2002) Sea-level and deep water temperature changes derived from benthic foraminifera isotopic records. Quaternary Sci Rev 21(1-3):295-305

Warrick R, Oerlemans J et al (1990) Sea level rise. In: Houghton JT, Jenkins GJ, Ephraums JJ (eds) Climate change. The IPCC Scientific Assessment. Cambridge University Press, Cambridge, pp 257-281

Zachos JC, Pagani M, Sloan L, Thomas E, Billups K (2001) Trends, rhythms, and aberrations in global climate $65 \mathrm{Ma}$ to present. Science 292:686-693 